Recebido em: 17 Abr. 2017 Aprovado em: 16 Jun. $2017 \quad$ Publicado em: 12 Set. 2017

DOI: https://doi.org/10.18554/rt.v10i1.2098

v. 10 n. 1 - Jan. / Jun. 2017

\title{
DOS LIVROS DIDÁTICOS AOS PROTÓTIPOS DE ENSINO: EM DIREÇÃO A UM WEB-CURRÍCULO
}

\author{
FROM TEXTBOOKS TO TEACHING PROTOTYPES: TOWARDS A WEB-CURRICULUM
DE LOS LIBROS DIDÁCTICOS A LOS PROTÓTIPOS DE ENSEÑANZA: EN DIRECCIÓN A UN WEB-CURRÍCULO

\author{
Fabiana Marsaro-Pavan \\ E-mail: fabiana.marsaro@gmail.com \\ Universidade Estadual de Campinas - UNICAMP
}

\begin{abstract}
RESUMO
Embora o desenvolvimento e a popularização das Tecnologias Digitais da Informação e da Comunicação (TDIC) as estejam aproximado cada vez mais da sala de aula, não podemos negar que elas ainda estão longe de integrar efetivamente o cotidiano escolar. Mesmo que nossa realidade seja cada vez mais on-line, digital, multissemiótica e plural, o que tem nos levado a questionar até mesmo o papel (e o futuro) da escola, os materiais mais tradicionais como livros didáticos, apostilados e sequências didática continuam a predominar. Neste artigo, buscaremos estabelecer um breve panorama do estado atual dos materiais didáticos mais presentes na escola pública brasileira, apontando por que eles nos parecem cada vez menos adequados para auxiliar na concretização de web-currículos, bem como descreveremos a proposta dos protótipos de ensino, discutindo se eles podem ser considerados uma alternativa de material didático para o contexto dos novos e dos multiletramentos.
\end{abstract}

PALAVRAS-CHAVE: Materiais didáticos. Protótipos de ensino. Web-currículos.

\begin{abstract}
Although the development and popularization of Digital Information and Communication Technologies are increasingly approaching them to the classroom, we cannot deny that they are still far from effectively integrating daily school. Even though our reality is increasingly more online, digital, multisemiotic and plural, which has even made us question the role (and the future) of school, more traditional materials such as textbooks, apostilles and didactic sequences continue to predominate. On this paper, we aim to establish a brief outlook of the status of the didactic materials that are present in Brazilian public schools, showing why they do not seem adequate to materialize a web-curriculum, as well as we will describe the teaching prototypes, arguing if they can be an alternative of didactic material in the context of the new and the multiliteracies.
\end{abstract}

KEYWORDS: Didactic Materials. Teaching Prototypes. Web-Curriculum.

\section{RESUMEN}

El desarrollo y la difusión de las Tecnologías Digitales de Información y Comunicación las acercan al aula, pero están aún lejos de integrar efectivamente la rutina de la escuela. Pese a que nuestra realidad sea cada vez más en línea, digital, multisemiotica y plural, lo que nos lleva a cuestionar el papel (y el futuro) de la escuela, predominan los materiales tradicionales como libros didácticos, apostillas y secuencias didácticas. En este artículo, presentamos un panorama de los materiales didácticos más utilizados en la escuela pública brasileña, demostrando por que ellos no parecen adecuados para auxiliar en la concreción de web-currículos, así como describimos la propuesta de los prototipos de enseñanza y discutimos si son una alternativa de material didáctico para el contexto de los nuevos y de los multiletramentos.

PALABRAS CLAVE: Materiales didácticos. Prototipos de enseñanza. Web-currículos. 


\section{INTRODUÇÃO}

As Tecnologias Digitais da Informação e da Comunicação (doravante TDIC) estão no centro de profundas transformações em nossas práticas sociais. Tudo mudou: nossa forma de ver e de criar, o jeito como agimos e nos relacionamos, os meios que temos para consumir e para reivindicar, nosso modo de ler e de escrever e, como não poderia deixar de ser, nossas demandas de ensino e de aprendizagem. Em uma realidade cada vez mais digital, on-line, multissemiótica e plural, na qual a informação e o conhecimento podem ser reproduzidos e distribuídos infinitamente, de forma instantânea e a custo praticamente zero, os papéis (e o futuro) da escola e dos materiais didáticos têm sido intensamente discutidos e, por vezes, questionados.

Mais do que um modismo ou uma tendência passageira, as TDIC, cada vez mais disseminadas e sofisticadas, têm engendrado uma verdadeira mudança de paradigma na educação, na medida em que alteram a lógica da leitura como a conhecíamos até então. Para Jay Lemke, hoje temos basicamente dois paradigmas de aprendizagem em conflito: o curricular e o interativo (LEMKE, 2010, p. 461).

O paradigma de aprendizagem curricular pode ser caracterizado como mais institucionalizado e predomina nas escolas e universidades. Ele parte do pressuposto de que "alguém decidirá o que você precisa saber e planejará para que você aprenda tudo em uma ordem fixa e em um cronograma fixo" (LEMKE, 2010, p. 461). Nesse paradigma, o planejamento quase sempre é de cima para baixo, o que resulta em processos de ensinoaprendizagem marcados pelo autoritarismo e pela rigidez, cada vez mais incompatíveis com a realidade contemporânea.

Já o paradigma de aprendizagem interativa assume que as pessoas podem definir a ordem e o tempo de suas aprendizagens. Ele domina instituições como as bibliotecas e os centros de pesquisa, contextos nos quais, geralmente, são as pessoas que determinam o que precisam saber, "baseando-se em suas participações em atividades em que essas necessidades surgem e em consulta a especialistas conhecedores" (LEMKE, 2010, p. 461). Para o autor, este é o paradigma daqueles que criaram a internet e o ciberespaço e é a forma como as pessoas com poder e com recursos escolhem aprender.

Embora saibamos que o paradigma de aprendizagem curricular tem fracassado e que o ideal seria caminhar em direção a um paradigma de aprendizagem interativa, podemos imaginar que essa ruptura não seja simples ou fácil, ainda mais no contexto da escola pública brasileira. Lemke acredita que as TDIC possibilitam que, em um futuro próximo, os alunos 
aprendam sem as escolas (LEMKE, 2010, p. 470). Em uma realidade como a nossa, no entanto, em que faltam boas conexões com a internet e professores adequadamente formados para o uso das TDIC e na qual o analfabetismo e a exclusão escolar ainda são desafios a enfrentar, parece ser mais viável falar em uma transição gradual e que não necessariamente rompa de imediato com o paradigma curricular.

Isso não significa reduzir a apropriação das TDIC pela escola a mera introdução de novos objetos de ensino ou de novas "disciplinas", mas sim considerar que, pelo menos em um primeiro momento, as TDIC devem ser articuladas aos saberes e procederes da escola tradicional. Uma das propostas nesse sentido é a construção daquilo que Almeida (2014) convencionou chamar de web-currículos, isto é, currículos escolares que, por meio da articulação e não da mera justaposição, efetivamente consideram e incluem essas tecnologias em sua elaboração, valendo-se de novas metodologias, ferramentas, recursos e materiais.

A concepção de web-currículo busca a "integração transversal das competências no domínio das TDIC com o currículo, pois este é o orientador das ações de uso das tecnologias" (ALMEIDA; SILVA, 2011, p. 8). Assim, implementar um web-currículo envolve observar o que é possível fazer com os recursos disponíveis e planejar ações viáveis que permitam que alunos, professores e gestores avancem gradativamente em direção à apropriação pedagógica das TDIC.

Em nossa pesquisa de Doutorado, que se encontra em sua fase inicial, temos buscado pensar a concepção de web-currículo em relação a outras teorias relevantes para o ensinoaprendizagem de língua materna, como os conceitos de novos e de multiletramentos, ao mesmo tempo em que analisamos uma proposta de material didático que pode ter potencial para auxiliar na sua efetivação: os protótipos de ensino.

Neste artigo, buscaremos estabelecer um breve panorama do estado atual dos materiais didáticos mais presentes na escola pública brasileira, apontando por que eles nos parecem cada vez menos adequados para auxiliar na concretização de web-currículos, bem como descreveremos a proposta dos protótipos de ensino, discutindo se eles podem ser considerados uma alternativa de material didático para o contexto dos novos e dos multiletramentos.

\section{REFERENCIAL TEÓRICO}

Os conceitos de novos e de multiletramentos são centrais na pesquisa que estamos desenvolvendo porque nos ajudam a compreender as demandas atuais para o ensino- 
aprendizagem de línguas, ao mesmo tempo em que permitem elaborar critérios para a análise de materiais didáticos, inclusive os protótipos de ensino que tomamos como objeto de estudo.

Os novos e os multiletramentos são duas interpretações diferentes, mas complementares, dos letramentos contemporâneos. Ambos surgem da perspectiva de que os letramentos são múltiplos e necessariamente desenvolvidos, construídos e vivenciados em práticas situadas histórico, social e culturalmente. Sendo assim, novas práticas fazem surgir novos letramentos, processo que têm se acelerado cada vez mais nas últimas décadas, com o desenvolvimento e a popularização das TDIC.

Entre as décadas de 1980 e 1990, os estudos do letramento avançaram no sentido de encarar as práticas mediadas pela leitura e pela escrita como culturais e socialmente situadas, o que levou à compreensão de que só se poderia falar em letramentos, no plural, múltiplos e diversificados. Em 1994, essa "multiplicidade" na abordagem dos letramentos foi consolidada com a definição do termo "multiletramentos", cunhado pelo autointitulado Grupo de Nova Londres.

Pensando que pedagogia poderia dar conta de uma realidade cada vez mais heterogênea e, ao mesmo tempo, tensa e complexa, os autores propõem que a pedagogia dos multiletramentos recubra essencialmente três âmbitos: o do trabalho, considerando a diversidade produtiva; o da cidadania, levando em conta o pluralismo cívico; e o da vida pessoal, contemplando as identidades multifacetadas (KALANTZIS; COPE, 2006 [2000]). Assim, para eles, a escola deveria formar trabalhadores flexíveis e suficientemente capacitados, capazes de se adaptar às constantes mudanças nos meios produtivos, e também cidadãos comprometidos com seu papel cívico, que adotem uma postura ética diante da diversidade.

A pedagogia dos multiletramentos é uma proposta interessante para a educação linguística contemporânea, principalmente quando sugere que sua materialização esteja centrada no conceito de design. Os autores defendem que, em um processo ativo e transformacional, os alunos devem considerar os designs disponíveis (sejam eles textos verbais escritos, imagens estáticas e em movimento, textos multissemióticos etc.) para desenvolver designs próprios e também se apropriar deles criticamente, em práticas de redesign (COPE; KALANTZIS, 2006[2000]).

O trabalho com os multiletramentos, dessa forma, prevê um ensino-aprendizagem de línguas que possibilite formar cidadãos críticos e situados, capazes de agir de forma consciente em suas realidades sociais e culturais. Para isso, não basta apenas desenvolver competências e habilidades técnicas, mas possibilitar que os alunos sejam leitores críticos, 
capazes não só de selecionar e de compreender diferentes enunciados, mas também de criar sentidos e de utilizar aquilo que aprenderam de novas formas.

Como já dissemos, as TDIC estão tornando novos letramentos tanto necessários quanto possíveis (LEMKE, 2010, p. 461), o que exige novas práticas e valores, uma vez que as tecnologias digitais possuem uma lógica diferente da que comandava os letramentos tradicionais/da letra. Em artigo de 2007, Lankshear e Knobel tentam responder o que é esse "novo" que caracteriza os "novos letramentos". De acordo com os autores,

os novos letramentos são, em sua essência, mais "participativos", "colaborativos" e "distribuídos" do que os letramentos convencionais. Ou seja, eles são menos "publicados", "individualizados" e "centralizados no autor" do que os letramentos convencionais. (LANKSHEAR; KNOBEL, 2007, p. 9, tradução nossa)

Para resultarem em novos "modos de fazer", porém, as possibilidades que o digital proporciona precisam vir acompanhadas de um novo ethos, termo de origem grega que pode ser interpretado como "novos modos de fazer". Assim, fica claro que a incorporação das tecnologias ao contexto escolar só tem sentido se, em vez de reproduzir práticas do letramento tradicional, as potencialidades das TDIC forem aproveitadas em práticas significativa e transformadoras.

Mesmo que as demandas de ensino-aprendizagem de língua materna já não sejam mais motivadas apenas pelo texto verbal escrito, na escola pública brasileira ainda predominam os livros didáticos impressos distribuídos pelo Programa Nacional do Livro Didático (PNLD) ${ }^{1}$. Para se ter ideia da dimensão do programa, basta observar os números da negociação do PNLD 2018, a edição mais recente, voltada para Ensino Médio. Entre reposições e novas aquisições, serão distribuídos aproximadamente 145 milhões de exemplares para mais de 32 milhões de alunos matriculados em 117 mil escolas públicas de todo o país, em uma operação que custará cerca de R $\$ 1,2$ bilhão aos cofres públicos ${ }^{2}$.

Sabemos que dificilmente o livro didático pode ser considerado o único norteador das ações didáticas e também que a simples presença desse tipo de material em sala de aula não é garantia de sua utilização, muito menos da maneira prevista por autores e editores. Como observado por Bunzen, "há mudanças de significado e de acento e até de distorções na apreciação cotidiana do livro didático" por professores e alunos e "seus usos podem ser tão múltiplos e as réplicas as mais diversas possíveis" (BUNZEN, 2009, p. 138). 
Apesar disso, o fato é que, enquanto política pública, é o PNLD que determina, há mais de duas décadas, a configuração dos materiais que circulam na rede pública brasileira, aí incluídas as iniciativas mais abrangentes em torno da incorporação das TDIC. Observando-se as investidas do MEC nessa área nos últimos anos, percebe-se uma sequência de ações descontinuadas. Embora, em um primeiro momento, tenha havido uma tentativa de se atrelar os livros didáticos impressos a materiais digitais, em poucos anos essas iniciativas recuaram.

Em 2012, no edital do PNLD 2014, o MEC incluiu pela primeira vez a demanda por objetos educacionais digitais complementares aos livros didáticos, que deveriam ser disponibilizados em DVD. Essa ação gerou a expectativa de que, gradualmente, o programa avançaria no sentido de superar as limitações próprias dos livros impressos que dificultam a aproximação com as TDIC, como o fato de serem pouco interativos e só contarem com o texto e a imagem estática, por exemplo.

No PNLD 2015, voltado para Ensino Médio, o edital ampliou o pedido e passou a solicitar obras multimídia, isto é, uma versão digital com o mesmo conteúdo dos materiais impressos, mas acrescida de objetos educacionais digitais, como vídeos, animações, simuladores, imagens, jogos, textos, entre outros itens para auxiliar na aprendizagem. Grande parte dos produtos elaborados pelas editoras para atender a essas demandas, no entanto, nem mesmo chegou às escolas, pois, sem atender aos critérios estabelecidos, foi considerada inadequada e reprovada nas avaliações ${ }^{3}$.

Em 2013, no contexto do PNLD 2016, destinado ao Ensino Fundamental I, aconteceu uma mudança importante, já que os objetos deixaram de ser destinados aos alunos e a demanda passou a ser por um "Manual do Professor Digital”, isto é, uma versão digital do Manual do Professor impresso, integrada a objetos educacionais digitais clicáveis na própria página (vídeos, imagens, áudios, textos, gráficos, tabelas, tutoriais, aplicações, mapas, jogos educacionais, animações, infográficos, páginas web e outros elementos), para uso individual do professor ou coletivamente com os alunos.

No PNLD 2017, para Ensino Fundamental II, o foco foi alterado mais uma vez e os objetos passaram a ser de uso exclusivo do professor, sendo proibidos "1. Audiovisuais em que o professor não possa controlar a sua execução; 2. Objetos educacionais que solicitam respostas de problemas ou atividades por meio da interação; 3. Atividades pedagógicas a serem desenvolvidas diretamente com os estudantes.” (BRASIL, 2015, p. 44). A orientação nesse edital era de que o "Manual do Professor Multimídia" deveria conter a reprodução do Manual impresso atrelada a conteúdos digitais, tais como animações e vídeos, voltados à abordagem, demonstração ou aprofundamento do estudo de metodologias, concepções, 
conteúdos ou conceitos, "com utilização de linguagem digital que o impresso não permite" (BRASIL, 2015, p. 4).

Já no último edital, referente ao PNLD 2018, para Ensino Médio, não foi solicitado nenhum tipo de material digital atrelado ao livro impresso, com exceção da versão em EPUB3 das obras selecionadas, a fim de atender demandas de acessibilidade (alunos surdos e com baixa visão, por exemplo). A ausência de uma demanda por material digital nesse edital deixou clara a descontinuidade nas tentativas de se incorporar as TDIC ao programa.

Soma-se a isso o fato de que, há algum tempo, o próprio formato do programa tem apresentado sinais de desgaste. Em junho de 2016, mesmo a manutenção do PNLD enquanto política pública foi colocada em xeque, já que atrasos no cronograma levaram a crer que havia o risco de o programa ser extinto pelo então ministro da Educação. O temor de que os alunos das escolas públicas ficassem sem livros didáticos e sem obras de literatura no ano letivo de 2017 levou à mobilização de diversos professores e pesquisadores em defesa do programa, por meio de petição on-line encaminhada ao $\mathrm{MEC}^{4}$.

Essa instabilidade no cronograma de execução do programa, agravada pela crise econômica que o país vem atravessando, também tem afetado a liberação de recursos às editoras, prejudicando principalmente as empresas menores e, com isso, levando a uma concentração ainda maior do mercado de didáticos, cada vez mais controlado pelo capital estrangeiro.

O oligopólio do setor, cuja formação iniciou-se na década de 1990, conforme aponta Cassiano (2007, p. 12), continua em plana expansão, algo muito preocupante na medida em que "sendo o objetivo principal das editoras a sobrevivência [...] a qualidade cultural e educativa passará a ser secundária, como ocorre em qualquer outro negócio" (CASSIANO, 2007, p. 8). O contexto de produção e de circulação dos livros didáticos, portanto, principalmente por conta da complexidade e das particularidades do PNLD, parece não favorecer a incorporação das TDIC e nem a elaboração de materiais que dialoguem com um paradigma de aprendizagem interativo.

Em outra frente, as mesmas grandes editoras que fornecem os livros didáticos para o PNLD produzem os chamados apostilados, sistemas de ensino ou sistemas estruturados, materiais que, desde os anos 2000, ao lado de outros impressos didáticos, têm ganhado cada vez mais espaço nas redes públicas, muitas vezes substituindo os livros didáticos distribuídos pelo governo.

Dados colhidos por Ilona Becskeházy e Paula Louzano, em pesquisa financiada pela Fundação Lemann, mostram que, em 2010, 46\% dos municípios do Estado de São Paulo 
usavam sistemas estruturados de ensino, sendo 34\% (505 mil alunos) utilizando sistemas privados e 12\% (705 mil alunos) utilizando sistemas públicos. Esses números representavam, à época, 1,2 milhão de alunos das redes municipais do Estado de São Paulo ou 50\% da matrícula municipal e $24 \%$ da matrícula de toda a rede pública (BECSKEHÁZY; LOUZANO, 2010, s/p).

Nessa pesquisa, as autoras procuram sustentar a tese de que o uso de sistemas de ensino por escolas públicas geraria melhoras nas notas da Prova Brasil. Para defender essa proposição, elas argumentam que os sistemas de ensino já são uma "solução amplamente adotada na rede privada nacional" e garantem maior exposição dos alunos ao conteúdo, melhor uso do tempo na sala de aula e maior controle do trabalho do professor (BECSKEHÁZY; LOUZANO, 2010, s/p).

Becskeházy e Louzano rebatem a ideia de que os sistemas de ensino ferem a autonomia e a liberdade do professor questionando se, de fato, elas existem. Elas citam uma pesquisa da Fundação Carlos Chagas que mostra que "os cursos de pedagogia não preparam os professores para dar aulas" e também pesquisa qualitativa feita pela Fundação Lemann, em 2008, que afirma que "quem está na linha de frente gosta de usar o material estruturado" (BECSKEHÁZY; LOUZANO, 2010, s/p).

Em uma perspectiva como essa, é claro, não cabem as ideias de autoria docente, de adaptação dos dispositivos didáticos à cultura local ou do professor mediador de um processo de ensino-aprendizagem autônomo e colaborativo. Pelo contrário, a apreciação de professor subjacente à pesquisa citada é a velha imagem do profissional mal formado, que não tem tempo (ou capacidade) de preparar suas aulas.

Indo de encontro a essa visão de professor, um recurso que ganhou muito espaço nas escolas nos últimos anos, principalmente no estado de São Paulo, foram as sequências didáticas, materiais que, por sua configuração, caracterizam-se como muito mais flexíveis aos usos e às escolhas dos docentes. Divulgado no Brasil principalmente pelas publicações dos trabalhos de Dolz, Schneuwly, Pasquier e Noverraz, pesquisadores da Universidade de Genebra, o conceito de sequência didática (SD) define "um conjunto de atividades escolares planejadas e organizadas, de maneira sistemática, em torno de um objeto de ensino (gêneros discursivos, no caso do ensino de Português como língua materna)" (ROJO, 2013, p. 176).

Uma vez que são bem mais curtas, as SD se configuram, de saída, como uma proposta mais maleável que a do livro didático, já que deixam o professor mais livre em relação ao tempo de uso do material. A sua organização em módulos, no entanto, acaba por impor 
algumas restrições, já que a elaboração destes deve estar totalmente direcionada ao contexto e às necessidades específicas dos alunos.

[...] se a autoria [da SD] for exógena, como a dos autores, de raiz acadêmica ou não, das SD distribuídas aos municípios e às capitais, certamente, de uma ou de outra maneira, a flexibilidade de uso e as possibilidades de escolha serão menores. (ROJO, 2013, p. 180)

Pensando que o cenário ideal para o uso das SD é aquele no qual o professor é também autor do material, podemos questionar sua viabilidade na realidade da escola brasileira, tendo em vista aspectos como a sobrecarga da jornada de trabalho, a falta de tempo para planejamento e as dificuldades logísticas de reprodução e de distribuição de materiais impressos pelo docente. Além do mais, podemos questionar se é apropriado delegar ao professor mais essa responsabilidade, já que dar uma aula é bem diferente de elaborar um material didático.

Tendo em vista esse contexto, observando os materiais disponíveis e buscando sugerir um novo modelo de recurso didático que pudesse, ao mesmo tempo, apoiar e formar professores para o trabalho com os novos e os multiletramentos, concretizando a concepção de web-currículos, Rojo propõe a elaboração de protótipos de ensino.

O conceito de protótipos de ensino, divulgado desde meados de 2011, nomeia e descreve "materiais digitais navegáveis (Ebooks, PDFs navegáveis) de apoio ao ensino, que combinam letramentos da letra e novos multiletramentos em projetos interdisciplinares" (ROJO, 2016a, p. 19). De acordo com a autora, embora se pareçam com as SD, os protótipos de ensino distinguem-se destas principalmente por conta de sua "arquitetônica vazada", isto é, de sua estrutura aberta e flexível, que pode ser preenchida pelo professor para atender a demandas específicas de cada contexto de ensino, catalisando o processo de autoria docente (ROJO, 2016a, p. 19).

Dentre as características dos protótipos de ensino definidas pela autora estão: a grande capacidade de armazenamento e a acessibilidade democrática, já que estão alocados nas nuvens; a utilização de ferramentas colaborativas públicas e gratuitas como o Prezi e o Google Docs, permitindo a interação colaborativa entre professores e alunos; o uso de ferramentas combinadas a banco de dados, facilitando a preparação das aulas pelo professor e garantindo a flexibilidade e a adaptabilidade dos materiais; a presença de princípios de ensino e de aprendizagem robustos; a estrutura hipertextual, hipermidiática e multimodal, que coloca 
semioses e mídias em diálogo e, finalmente, o caráter multicultural que, emprestando o conceito de García-Canclini (2008[1989]), sempre combina diferentes coleções culturais.

Para Rojo, os protótipos de ensino são "uma solução intermediária entre as SD e o professor produzir seus próprios materiais" (ROJO, 2016a, p. 26) e podem ser definidos como "esqueletos" a serem preenchidos levando-se em conta as particularidades do contexto de ensino. Esse "esqueleto", ao fornecer ao professor princípios de ensino-aprendizagem consistentes, ajudaria a conduzir o processo de autoria docente.

Em 2015, no contexto do projeto "Protótipos didáticos digitais para os multiletramentos e novos letramentos nos anos iniciais do Ensino Fundamental (EF1)", Rojo coordenou a produção de 20 protótipos de ensino interdisciplinares e baseados em pedagogia de projetos destinados ao Ensino Fundamental I das Escolas de Ensino Integral da Secretaria da Educação do Estado de São Paulo. A demanda pela elaboração dos protótipos - cujos autores foram estudantes especiais, mestrandos e doutorandos do Programa de PósGraduação em Linguística Aplicada do IEL/UNICAMP - partiu da SEE-SP, tendo como objetivo sua posterior utilização nas escolas que atendem ao Novo Modelo de Escola de Tempo Integral, oferecido a cerca de 80 mil alunos em 297 unidades da rede estadual de São Paulo.

Embora problemas técnicos e de infraestrutura da rede tenham impedido a implementação do conjunto de protótipos em sala de aula, como estava previsto, sua elaboração foi uma oportunidade de materializar pela primeira vez o conceito, o que nos oferece a possibilidade de analisar mais concretamente a viabilidade e as potencialidades da proposta.

\section{MATERIAIS E MÉTODOS}

A pesquisa que estamos desenvolvendo está situada no campo da Linguística Aplicada (LA), que tem como um de seus objetos de estudo os discursos didáticos. Nosso objetivo é investigar se os protótipos de ensino podem ser uma alternativa interessante de material didático para o contexto dos novos e dos multiletramentos, com potencial ou não para ajudar a viabilizar web-currículos.

Em uma perspectiva qualitativa, analisaremos o conjunto de 20 protótipos de ensino produzidos em 2015 por estudantes especiais, mestrandos e doutorandos do Programa de PósGraduação em Linguística Aplicada do IEL/UNICAMP, sob coordenação da $\operatorname{Prof}^{\mathrm{a}} \operatorname{Dr}^{\mathrm{a}}$ Roxane Rojo, em atendimento à demanda da Secretaria da Educação do Estado de São Paulo. 
A análise procurará responder se os protótipos produzidos efetivamente realizam a ideia de "protótipo de ensino" em sua concepção inicial. Se sim, tentaremos descrever como o fazem. Se não, procuraremos justificar por que os materiais produzidos não podem ser caracterizados de tal forma.

Até o momento, prevemos a necessidade de duas etapas de trabalho. Na primeira, faremos a análise preliminar dos 20 protótipos, com o objetivo de observar e descrever os temas, gêneros, ferramentas/mídias, pedagogia e design mobilizados por cada um. Na segunda etapa, tendo em vista as hipóteses e questionamentos resultantes da realização da primeira, selecionaremos, no conjunto de protótipos, aqueles que nos parecerem mais e menos favoráveis às práticas de ensino-aprendizagem dos novos multiletramentos em webcurrículos, observando-os mais detalhadamente para tentar identificar aquilo que os caracteriza de uma ou de outra forma.

\section{ANÁLISE DOS DADOS E RESULTADOS}

Nossa pesquisa está em estágio inicial e vem sendo desenvolvida no âmbito do Programa de Pós-Graduação em Linguística Aplicada do Instituto de Estudos da Linguagem da Universidade Estadual de Campinas, na área de Linguagem e Educação.

Partimos do pressuposto de que, por suas características e pelo referencial teórico sobre o qual estão embasados, os protótipos de ensino poderiam se configurar como "uma solução interessante para materiais didáticos de apoio e formação do(a) professor(a) para as práticas de ensino-aprendizagem dos novos multiletramentos em um web-currículo" (ROJO, 2016a, p. 6).

A análise dos dados gerados nas duas etapas descritas anteriormente procurará identificar se os 20 protótipos produzidos podem ser caracterizados de acordo com o conceito definido por Rojo, bem como apontar quais características presentes ou ausentes nesses materiais os tornam mais ou menos favoráveis ao fomento dos novos e dos multiletramentos no contexto de web-currículos.

Uma das hipóteses com que trabalhamos é que, por conta das limitações técnicas, orçamentárias e de formação de seus autores, os protótipos produzidos ainda se assemelham muito a uma SD tradicional. Embora uma das vantagens dos protótipos em relação a outros tipos de materiais didáticos seja não necessitar de ferramentas técnicas avançadas para sua elaboração, já que podem ser diagramados como PDFs navegáveis, o ideal seria materializá- 
los na forma de livros digitais interativos (LDDI), dispositivos cujas características principais são a interatividade e a hipermídia.

O termo "interativo" no nome dos LDDI não é pouco importante, na medida em que indica a interatividade conectada que cada um desses materiais (seja LDDI, seja plano de aula, gamificação etc.) precisa ter para que o usuário possa fazer suas escolhas mais interessantes de percurso, assim como navegar pela $W e b$. Trata-se de interatividade com a mídia e de interatividade com outros usuários remotos ou presentes no mesmo espaço físico, conforme requer uma pedagogia colaborativa por design (ROJO, 2016b, p. $16)$.

No formato de livros digitais interativos, os protótipos permitiriam "interatividade com o material, navegação, multissemiose e hipermídia, de maneira muito fácil (semelhante à edição de um PowerPoint)". Associados a um "discurso autoral/professoral", esses recursos poderiam conduzir "os alunos a um trabalho digital aberto, investigativo e colaborativo, mediado pelo professor" (ROJO, 2016b, p. 18).

Uma outra hipótese que temos é em relação à escolha dos temas e dos gêneros selecionados para compor o "esqueleto" dos protótipos produzidos. Parece-nos que gêneros mais ligados aos letramentos da letra, como os literários, por exemplo, acabam limitando o fomento dos novos e dos multiletramentos. Por outro lado, os protótipos elaborados em torno de temas transversais, em uma perspectiva interdisciplinar, parecem oferecer mais possibilidades de articulação entre os letramentos tradicionais e as TDIC, o que pode ser considerado mais interessante quando se pensa na efetivação de um web-currículo.

\section{CONSIDERAÇÕES FINAIS}

Como procuramos discutir ao longo deste texto, embora o desenvolvimento e a popularização das TDIC as estejam aproximando cada vez mais da sala de aula, não podemos negar que elas ainda estão longe de integrar efetivamente o cotidiano da escola brasileira, principalmente pública. Os materiais impressos continuam a prevalecer, ainda que, por vezes, dividam espaço com computadores, tablets ou objetos digitais de aprendizagem.

Seja no formato de livros didáticos, sistemas de ensino ou sequências didáticas, associadas ou não a objetos ou plataformas digitais, ainda percebemos que esses materiais são, em sua maioria, bastante fechados, e que não necessariamente consideram a realidade dos alunos e seus conhecimentos prévios a respeito das TDIC, muito menos proveem a 
necessária renovação metodológica ou incentivam e orientam os professores a realizar buscas autônomas, adaptar conteúdos fornecidos e desenvolver materiais próprios.

Assim, embora existam, essas iniciativas não têm provocado mudanças efetivas nas práticas de ensino-aprendizagem. Nesse sentido, o ideal seria que a escola buscasse, cada vez mais, materializar e viabilizar propostas de ensino-aprendizagem no bojo daquilo que Rojo chama de novos multiletramentos: "aqueles que além de se valerem de TDIC e de diversas linguagens/culturas, ainda operam em sua produção, circulação e recepção a partir de uma Mentalidade 2.0" (ROJO, 2016a, p. 13). Desse modo,

faz-se necessário complementar a matriz curricular na direção de contemplar os novos multiletramentos em termos de diversidades de mídias, linguagens e culturas, de forma articulada com os conteúdos e expectativas de aprendizagem propostos para as disciplinas e áreas do currículo. (ROJO, 2016a, p. 6)

O conceito de web-currículo mostra-se útil nesse contexto, já que, em vez de propor uma ruptura radical com o paradigma curricular, sugere a articulação gradual das novas tecnologias aos saberes e procederes da escola tradicional, de modo que a apropriação pedagógica das TDIC aconteça de forma progressiva, o que nos parece muito mais viável tendo em vista a realidade brasileira.

Sem ignorar o potencial que outros tipos de materiais didáticos têm para integrar práticas significativas de ensino-aprendizagem, em nossa pesquisa tomamos como objeto especificamente os protótipos de ensino. Concebidos como uma proposta de recurso didático que poderia ajudar a viabilizar web-currículos no contexto dos novos e dos multiletramentos, os protótipos de ensino só foram materializados pela primeira vez recentemente, o que nos dá chance de investigar em que medida eles atendem ou não ao propósito para o qual foram inicialmente pensados.

Embora possam, futuramente, ser aprimorados na forma de livros digitais interativos, os protótipos de ensino não deixam de ser um exemplo interessante de um novo tipo de material didático que, valendo-se dos recursos disponíveis, busca avançar em direção àquilo que está sendo discutido pelas teorias mais recentes, o que é um exercício bastante necessário no período de transição em que vivemos.

\section{NOTAS}

1. Criado por meio do Decreto 91.542, de 19/08/1985, o PNLD é um dos maiores programas para compra e distribuição gratuita de livros didáticos do mundo. A partir de 1996, o Programa passou também a avaliar as obras inscritas. 
2. Dados disponíveis em: <http://www.publishnews.com.br/materias/2016/12/05/fnde-devera-investir-r-13bilhao-em-aquisicao-de-livros-para-o-pnld-2017>. Acesso em: 5 dez. 2016.

3. Os resultados da avaliação pedagógica das obras impressas e digitais inscritas no PNLD podem ser consultados no portal do FNDE: < http://www.fnde.gov.br/programas/livro-didatico/guias-do-pnld>, acesso em: 21 out. 2016.

4. Disponível em:

$<$ https://secure.avaaz.org/po/petition/Ministerio_da_Educacao_gabinetedoministromecgovbr_Regularizar_e_ma nter_o_andamento_do_PNLD_e_do_PNBE/?pv=14 $>$. Acesso em: $6 \mathrm{dez} .2016$.

\section{REFERÊNCIAS}

ALMEIDA, M. E. B. Integração currículo e tecnologias: concepção e possibilidades de criação de web currículo. In: ALMEIDA, M. E. B.; ALVES, R. M. A.; LEMOS, S. D. V. (Orgs.). Web Currículo: aprendizagem, pesquisa e conhecimento com o uso de tecnologias digitais. Rio de Janeiro: Letra Capital, 2014.

ALMEIDA, M. E. B.; SILVA, M. G. M. Currículo, tecnologia e cultura digital: espaços e tempos de web currículo. Revista e-Curriculum, v. 7. São Paulo: PUC-SP, 2011.

BECSKEHÁZY, I.; LOUZANO, P. Sala de aula estruturada: O impacto do uso de sistemas de ensino nos resultados da Prova Brasil - um estudo quantitativo no estado de São Paulo. São Paulo: Fundação Lemman, 2010. Disponível em: $<$ http://www.fundacaolemann.org.br/uploads/estudos/sala_de_aula_estruturada_ilona_becske hazy_e_paula_louzano.pdf>. Acesso em: 31 out. 2016.

BRASIL. Edital de convocação para o processo de inscrição e avaliação de obras didáticas para o Programa Nacional do Livro Didático - PNLD 2017. Brasília: MEC/FNDE/SEB, 2015.

BUZEN, C. Dinâmicas discursivas na sala de aula: os usos do livro didático e projetos didáticos autorais. Tese (Doutorado). Universidade Estadual de Campinas, 2009.

CASSIANO, C. F. O mercado do livro didático no Brasil: da criação do Programa Nacional do Livro Didático (PNLD) à entrada do capital internacional espanhol (1985-2007). Tese (Doutorado). Pontifícia Universidade Católica de São Paulo (PUC-SP), 2007.

COPE, B.; KALANTZIS, M. Designs for social futures. In: COPE, B.; KALANTZIS, M. (Eds). Multiliteracies: Literacy Learning and the design of social futures. Nova York: Routledge, 2006[2000], p. 203-234.

GARCÍA-CANCLINI, N. Culturas Híbridas: Estratégias para entrar e sair da modernidade. São Paulo: Edusp, 2008[1989].

KALANTZIS, M; COPE, B. Changing the Role of Schools. In: COPE, B; KALANTZIS, M. (Orgs.). Multiliteracies: literacy learning and the design of social futures. Nova York: Routledge, 2006 [2000], p. 121-148; 235-289.

LANKSHEAR, C.; KNOBEL, M. Sampling "the New" in New Literacies. In: KNOBEL, M.; LANKSHEAR, C. (Orgs.). A New Literacies Sampler. New York: Peter Lang, 2007, p.124. 
LEMKE, J. L. Letramento metamidiático: transformando significados e mídias. Trabalhos em Linguística Aplicada, Campinas, v. 49, n. 2, p. 455-479, dez. 2010. Disponível em: $<$ http://www.scielo.br/scielo.php?script=sci_arttext\&pid=S0103-

18132010000200009\&lng=en\&nrm=iso>. Acesso em: 7 dez. 2016.

ROJO, R. H. R. Materiais didáticos no ensino de línguas. In MOITA-LOPES, L. P. da (Org.). Linguística Aplicada na modernidade recente - Festschrift para Antonieta Celani. São Paulo, SP: Parábola Editorial/Cultura Inglesa, 2013. P. 163-195.

ROJO, R. H. R. Novos multiletramentos e protótipos de ensino: por um Web-Currículo/New multiliteracies and teaching prototypes: for a Web-Curriculum. Linguagem em (Dis)curso (Impresso), 2016a.

ROJO, R. H. R. Entre Plataformas, ODAs e Protótipos: Novos multiletramentos em tempos de WEB2. Campinas, SP: Pontes, 2016b. 